Artigo original

Hegemonia - Revista Eletrônica de Relações Internacionais do Centro Universitário Unieuro

ISSN: 1809-1261

UNIEURO, Brasília, número 5, 2010

Recebido em: 10/11/2009

Revisado em: 25/11/2009

Aprovado em: 13/2/2010

\title{
ABIN: DA INFORMAÇÃO À INTELIGÊNCIA. A EVOLUÇÃO DO SERVIÇO DE INTELIGÂNCIA BRASILEIRO E SUA IMPORTÂNCIA NA PROTEÇÃO DO ESTADO
}

DA COSTA, Rafael Araújo ${ }^{1}$

\begin{abstract}
Resumo: O presente trabalho tem por objetivo o estudo da Atividade de Inteligência de Estado. Para tanto foi escolhida como objeto a Agência Brasileira de Inteligência, criada por meio da Lei n. ${ }^{\circ}$ 9.883, de 07 de dezembro de 1999, com a missão de planejar, executar, coordenar, supervisionar e controlar as atividades de inteligência no Brasil. O trabalho mostra a evolução do serviço de inteligência nacional e as influências recebidas dos serviços de inteligência internacionais, como a Central Intelligence Agency (CIA), dos Estados Unidos, buscando a reflexão sobre o conceito de inteligência e relacionando-o ao adotado pelo Estado brasileiro, para fins de cumprir sua missão institucional - a proteção do próprio Estado e do povo brasileiro.
\end{abstract}

Palavras-chaves: atividade de inteligência; segurança internacional; serviços secretos; Agência Brasileira de Inteligência (ABIN).

\begin{abstract}
This work was study the activity of the State Intelligence. So it was chosen as the Brazilian Intelligence Agency, established by Law No. 9883, 07 December 1999, with the mission to plan, implement, coordinate, supervise and control the activities of intelligence in Brazil. The work shows the development of the national intelligence service and the influences received from the intelligence services, such as the Central Intelligence Agency (CIA), of United States, seeking to reflect on the concept of intelligence, relating it to the system adopted by the Brazilian state , in order to fulfill its institutional mission - the protection of the state and the Brazilian people.
\end{abstract}

Key-words: Intelligence; International security; Secret services; Brazilian Intelligence Agency (ABIN).

\section{Introdução}

A questão da segurança e da proteção do Estado Nacional, sob o ângulo interno e internacional é o tema deste estudo. Para tanto, elegemos como objeto a Agência Brasileira de Inteligência, ABIN, criada em 1999, para executar e controlar as políticas de Inteligência, estabelecidas pelas autoridades competentes para o Brasil contemporâneo.

O objetivo principal do estudo é a reflexão sobre o conceito de Inteligência, relacionando-o ao sistema adotado pelo Estado brasileiro para fins de sua proteção. Pretende-se, ainda,

1 Bacharel em Relações Internacionais. Consultor na Câmara dos Deputados. 
Artigo original

Hegemonia - Revista Eletrônica de Relações Internacionais do Centro Universitário Unieuro

ISSN: 1809-1261

UNIEURO, Brasília, número 5, 2010

compreender o contexto que levou à criação da ABIN, analisar a forma de funcionamento e os objetivos e estratégias que a instituição utiliza.

Nesse sentido, o foco central deste estudo é a questão da segurança construída pelo Estado brasileiro, hoje permeada por "perigos difusos", e todos os seus desdobramentos nas décadas pós Guerra-Fria e no contexto global. Com esse enfoque procurou-se responder às seguintes questões: qual entendimento que tem hoje o Estado Brasileiro sobre a atividade de inteligência? $\mathrm{O}$ que a sociedade tem a ganhar com a melhoria dos serviços de inteligência? Quais são os principais problemas encontrados pela agência no campo legal e operacional? Quais melhorias podem acarretar para a agência e para a sociedade um melhor controle externo das atividades de inteligência?

Uma vez que o tema refere-se à questão da segurança nacional no contexto global, a abordagem do problema foi feita principalmente à luz das contribuições de Antunes, (2002), Pecequilo, (2004), Morgenthau, (2003), Sarfati, (2005) e Gonçalves, (2008). Para auxiliar este estudo, foi realizada ainda uma entrevista com o professor Dr. Roniere Ribeiro do Amaral, da Escola de Inteligência da Agência Brasileira de Inteligência.

O estudo é relevante por analisar uma questão - segurança - que além de atual, é prioritária no mundo globalizado e permeia as reflexões, ações e práticas governamentais nacionais e internacionais em tempos de extrema competitividade política, social e comercial, imersos em incertezas e ameaças de todas as ordens. Daí a importância dessa discussão para o conhecimento das relações internacionais.

Este trabalho encontra-se organizado da seguinte forma: primeiro abordamos os conceitos de segurança e inteligência sob o arcabouço teórico das relações internacionais, principalmente a partir da Teoria Realista e seus principais representantes. Ao avançarmos, analisamos as raízes da idéia de inteligência nacional, mostrando que influências externas foram absorvidas e constituíram a estrutura técnica e filosófica da Inteligência do Brasil. Prosseguimos no estudo da parte histórica, buscando investigar o papel do extinto Serviço Nacional de Informações (SNI), a conjuntura política e social na qual a instituição foi criada e inserida, suas atividades, dificuldades, sua ação e trajetória até a criação, em 1999, da Agência Brasileira de Inteligência, ABIN.

Na sequiência, analisamos os propósitos e práticas da $\mathrm{ABIN}$, foco principal da terceira parte deste estudo, para melhor compreendermos as atuais concepções do Estado brasileiro sobre questões como segurança, proteção e inteligência.

Para o estudo dos fatos concretos, articulamos as questões inicialmente propostas, 
Artigo original

Hegemonia - Revista Eletrônica de Relações Internacionais do Centro Universitário Unieuro

ISSN: 1809-1261

UNIEURO, Brasília, número 5, 2010

examinando os fatos atuais que envolvem e requisitam as atividades de inteligência e suas implicações.

\section{Segurança e Relações Internacionais}

Analisaremos a questão da segurança do Estado sob a ótica da Teoria Realista, particularmente a partir das formulações de autores como Nicolau Maquiavel, Tomas Hobbes, Carl Von Clausewitz, Edward Carr e Hans Morgenthau. Todos esses pensadores se dedicaram a entender e explicar o fato maior que dá início ao estudo da segurança: a guerra. Esta primeira parte do trabalho tem por objetivo mostrar, diante das inúmeras transformações que são apresentadas todos os dias, como se deu o surgimento das primeiras agências de inteligência, qual o contexto de sua criação e influências deixadas para as agências atuais.

Primeiramente é preciso compreender algumas premissas comuns ao pensamento realista. $\mathrm{O}$ Sistema Internacional (SI) é regido por uma anarquia, conforme cita Pecequilo:

“A anarquia corresponde à ausência de um governo e de leis que definem parâmetros de comportamento e regulagem de um determinado espaço, provendo-lhe ordem. No SI a ordem nasce das relações que se estabelecerão entre os atores e sua dinâmica, predominando a lógica da competitividade e da sobrevivência, do choque de interesses. Tais choques levarão a um cenário de perfil incerto que dependendo do contexto, da época e dos atores envolvidos oscilará entre dois eixos básicos, o da cooperação e do conflito. $\mathrm{O}$ poder será o definidor das Relações Internacionais." (2004:38)

Pecequilo mostra que os Estados possuem total controle dentro de seu território, como prerrogativa da soberania, mas não o possuem fora dele. Em virtude dessa soberania não deve existir um que seja controlador do sistema internacional, pois seus interesses poderiam não ser convergentes com os interesses dos demais Estados Soberanos ${ }^{2}$.

O primeiro autor a enfatizar o tema "soberania" foi o francês Jean Bodin (1529-1596) em

2 O Tratado de Westfália em 1648, que restabeleceu a paz na Europa, proporcionou a liberdade jurídica dos Estados, colocando-os como únicos atores nas políticas internacionais. 
Artigo original

Hegemonia - Revista Eletrônica de Relações Internacionais do Centro Universitário Unieuro ISSN: 1809-1261

UNIEURO, Brasília, número 5, 2010

sua obra "Os Seis Livros da República". Nele propõe-se que a soberania é um poder perpétuo e possui como únicas limitações a lei divina e a lei natural. Dentro dessas limitações, o poder do Estado seria absoluto. Segundo Hobbes, (1974), a soberania ocorre porque os homens abrem mão de seu poder e o incumbe para uma única pessoa, fato que as obriga a obedecer a tudo que o detentor do poder ordenar. Como essa transferência do poder parte dos súditos, Hobbes acredita que a soberania criada dessa transferência seja absoluta, ilimitada e irrevogável.

A existência de Estados Soberanos no sistema internacional leva portanto à necessidade da criação de instrumentos que preservem o equilíbrio em busca da manutenção da paz.

A palavra equilíbrio, do latim aequilibriu, segundo o Dicionário Houaiss da Língua Portuguesa (2004) pode ser definida como: 1. posição estável de um corpo; 2. igualdade entre forças opostas; 3. distribuição harmoniosa; 4. Estado do que se mantém inalterado. Estabilidade; 5. Autocontrole, autodomínio. Seguindo esse fluxo, o sistema internacional também funciona por meio de um processo de equilíbrio, entre o poder do Estado mais forte e a falta de poder do Estado mais fraco. Segundo Morgenthau (1996), quando esse equilíbrio é quebrado, seja por motivos externos ou pela atuação de um ou mais elementos do sistema, este tende a restabelecer o equilíbrio anterior ou instaurar um novo equilíbrio. Pecequilo diz que a busca do equilíbrio não ocorre pelo fato dos Estados se preocuparem com a paz, mas sim pela prevenção do surgimento de um poder hegemônico que subjugue os demais. Nem sempre o status quo deixa os Estados satisfeitos, mas para que possam garantir sua sobrevivência devem conservá-lo, pois garante a eles margem de manobra para buscarem seus objetivos.

Todos os Estados, na luta por sua sobrevivência, participam diuturnamente deste enorme jogo, baseado na lógica do soma zero, onde para que um obtenha êxito é necessário que o outro perca. Diante dessa enorme pressão constante no Sistema Internacional, o equilíbrio de poder aparece como resposta natural a estes dilemas.

\section{Inteligência e Espionagem Internacional: Serviços Secretos}

$\mathrm{Na}$ expectativa de manter esse equilíbrio do Sistema Internacional os diversos Estados buscam, cada um à sua maneira, obter vantagens baseadas em fraquezas de seus adversários diretos. Com esse intuito várias nações criaram, no decorrer dos anos, agências ou organismos estatais que tinham como principal função o controle interno e externo de ameaças. Muitas dessas agências possuíam o caráter de polícia política. Essas agências tiveram grande influência nas decisões dos 
Artigo original

Hegemonia - Revista Eletrônica de Relações Internacionais do Centro Universitário Unieuro

ISSN: 1809-1261

UNIEURO, Brasília, número 5, 2010

Estados no período entre o início da II Guerra Mundial (1939-1945) e o fim da Guerra Fria (19451991).

$\mathrm{Na}$ União das Repúblicas Socialistas Soviéticas, referida neste trabalho apenas por sua sigla URSS, é importante ressaltar a existência de duas agências, o NKVD e o KGB. O NKVD ${ }^{3}$, criado em 1934 e atuando até 1946, possuía a função de coordenar as políticas de repressão durante o regime de Stalin. Era conhecida como polícia secreta e política do Partido Comunista da União Soviética. Em sua área de atuação constava somente o território da URSS. O $\mathrm{KGB}^{4}$, criado em 1954 e tendo suas atividades executadas até meados de 1991, é considerada a maior e mais organizada agência de espionagem da URSS. Com sua estrutura semelhante à de um ministério, possuía cinco direções principais, sendo a primeira a mais importante que incluía a subdireção dos ilegais; a subdireção cientifica e técnica; um serviço de contra-espionagem; serviço de ação e um serviço dos negócios sujos, responsável por assassinatos e seqüestros. A segunda e terceira direçõesgerais eram encarregadas da informação, vigilância e da repressão interna, a quarta dos guardas da fronteira, e a quinta, das escolas. Seu quadro efetivo chegou a mais de trezentos mil soldados, possuía também blindados e caças.

A Alemanha também teve sua polícia política bastante atuante. Instituída em 26 de abril de 1933, na Prússia, a Gestapo ${ }^{5}$ era apenas um braço da polícia prussiana. Seu papel como polícia

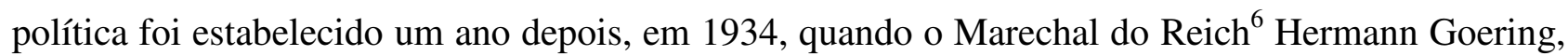
tido como o segundo mais importante na hierarquia do regime nazista, assumiu seu comando. A Gestapo também possuía uma estrutura muito bem organizada, semelhante à KGB. Com cinco departamentos base, a organização não possuía limites para a investigação e apreensão de suspeito, utilizando, inclusive, técnicas de tortura. Seus departamentos eram departamento A, inimigos; departamento B, seitas e igrejas; departamento C, administração; departamento D, territórios ocupados e departamento E, contra-espionagem.

$\mathrm{Na}$ Inglaterra, o serviço secreto não atuou como polícia política. A principal unidade britânica $\mathrm{MI}^{7}$, que atuava no âmbito interno e ocasionalmente apoiava missões externas, tinha

3 Russo: НКВД, Народный комиссариат внутренних дел, Narodniy komissariat vnutrennikh del; português: comissariado popular de assuntos internos; em: http://pt.wikipedia.org.

4 Russo: КГБ, Komitet Gosudarstveno Bezopasnosti, Komityet Gosudarstvennoy Bezopasnosty, português: Comitê de Segurança do Estado; em: http://pt.wikipedia.org.

5 Alemão: Geheime Staatspolizei, português: polícia secreta do Estado; em: http://pt.wikipedia.org.

6 Alemão: Reichsmarschall; foi a mais alta patente das Forças Armadas do Sacro Império Romano-Germânico e da Alemanha Nazi. Durante a II Guerra Mundial a patente foi usada pelo segundo homem na hierarquia da nação.

Military Intelligence, section 5, em: http://pt.wikipedia.org. 
Artigo original

Hegemonia - Revista Eletrônica de Relações Internacionais do Centro Universitário Unieuro ISSN: 1809-1261

UNIEURO, Brasília, número 5, 2010

como funções principais a defesa da democracia parlamentar, dos interesses econômicos e o combate à alta criminalidade, incluindo tentativas de separatismo, o terrorismo e as atividades de contra-espionagem.

A mais conhecida agência secreta é a agência americana. Criada em 1947, pelo então Presidente dos Estados Unidos, Harry S. Truman (1884-1972) através do National Security Act. A $\mathrm{CIA}^{8}$, agência civil, independente e sem poder de polícia, tinha, entre outros, o objetivo de conter o avanço do comunismo. Proibida por lei de investigar cidadãos americanos dentro dos Estados Unidos, a agência atua somente fora de seu território. A função de investigação interna é desempenhada pelo $\mathrm{FBI}^{9}$, órgão equivalente no Brasil à Polícia Federal. A CIA desempenhou tão importante papel para a política externa americana que não foi extinta, como muitas que atuavam no período da Guerra Fria, conforme cita Gonçalves:

"Interessante observar o papel da CIA na Política Externa dos EUA que, durante a Guerra Fria, centrou-se na reunião de dados, análise e produção de conhecimento e difusão de inteligência aos tomadores de decisão e formuladores de políticas, como o NSC e os Departamentos de Estado e de Defesa. O Presidente dos EUA e demais altas autoridades do governo eram supridos com relatórios periódicos - no caso do Presidente, diários produzidos pela comunidade de inteligência e repassados ao DCI. Os temas envolviam de que questões relativas à política interna da URSS e dos países do bloco socialista e temas econômicos e até interesses dos EUA junto a aliados e países do Ocidente." (2008:79)

Sua estrutura também muito organizada divide-se em cinco diretorias: Diretoria de Inteligência Central no Congresso, Diretoria Executiva da Agência de Inteligência Central, Diretoria de Inteligência, Diretoria de Ciência e Tecnologia e Diretoria Operacional; um Centro de Estudos de Inteligência e materiais históricos e estatística e dois escritórios - Escritório de Deliberação Geral e Escritório de Negócios Públicos. Apesar da grande estrutura, a CIA não é a 
Artigo original

Hegemonia - Revista Eletrônica de Relações Internacionais do Centro Universitário Unieuro

ISSN: 1809-1261

UNIEURO, Brasília, número 5, 2010

única agência norte-americana responsável pela atividade de inteligência. A comunidade de inteligência dos Estados Unidos conta atualmente com cerca de 16 grandes agências independentes, mas que se relacionam buscando melhor eficiência dos serviços de inteligência.

Com a divisão do mundo em blocos e o início da Guerra Fria, tanto os Estados Unidos quanto a União Soviética precisavam fortalecer seus sistemas e serviços para que fossem capazes de fornecer ao governo informações precisas e confiáveis. Com isso o sistema de informações soviético foi gradativamente ampliando sua presença em outros países. O ano de 1954 foi fundamental nesse processo. Laurenti Beria ${ }^{10}$, o principal responsável por tornar a agência uma das mais temidas e repressoras da história, usou dos mecanismos da agência para eliminar opositores e dissidentes, Gonçalves (2008:72) faz grande referência a esse período informando, inclusive, o assassinato do maior rival de Stálin, Leon Trotski (1879-1940), morto em sua casa no México, onde se encontrava exilado. Após a morte de Joseph Stálin, ocorrida em 05 de março de 1953, Beria tentou tomar o poder, mas não obteve êxito e acabou executado por ordem da cúpula do Partido Comunista, reformulando após toda a estrutura do serviço secreto.

Desde o final da II Guerra Mundial até 1990, com a queda do Muro de Berlim, tido como o maior símbolo da Guerra Fria, o mundo presenciou intensa disputa pela hegemonia mundial entre Estados Unidos e URSS. Com o objetivo de conquistar zonas de influência, essas potências travaram uma intensa guerra econômica, diplomática e tecnológica. Essa disputa dividiu o mundo em dois blocos, formados por sistemas econômicos e políticos opostos: o bloco capitalista, liderado pelos Estados Unidos, e o bloco comunista, liderado pela União Soviética. Por mais de quarenta anos foi estabelecida uma corrida armamentista que colocou o mundo sob a forte ameaça de uma guerra nuclear.

Um momento que pode ser destacado, pela tensão que o envolveu, é o caso conhecido como “A Crise dos Mísseis de Cuba”. A reportagem especial da revista Veja, de outubro de 1962, intitulada "O dia em que chegamos perto do fim" relatou o fato de que o governo russo estava instalando mísseis nucleares em Cuba: ${ }^{11}$

"Em julho último, a inteligência americana notou um súbito aumento no número de navios soviéticos a caminho de Cuba hoje, acredita-se que tenha sido esse o período de início da montagem dos mísseis. O secretário de Defesa, Robert

\footnotetext{
10 Policial-chefe, assessor de Stalin, preso e fuzilado em setembro de 1953.
}

11 http://veja.abril.com.br. 
Artigo original

Hegemonia - Revista Eletrônica de Relações Internacionais do Centro Universitário Unieuro ISSN: 1809-1261

UNIEURO, Brasília, número 5, 2010

McNamara, ordenou que a movimentação fosse seguida de perto. Apesar dos indícios suspeitíssimos, Kennedy e seus auxiliares caíram no conto de Kruschev, que jurava de pés juntos que a URSS não colocaria armas em Cuba. No mês passado, Kennedy visitou o Congresso e assegurou que não havia mísseis de ataque na ilha. No mesmo dia, o secretário de Justiça, Robert Kennedy, ouvia essa mesma garantia do embaixador soviético, Anatoly Dobrynin. Kruschev procurou Kennedy pessoalmente naquela semana e repetiu: não interessava aos soviéticos espalhar seu poderio bélico mundo afora. Mas a montagem do arsenal era tão evidente que a própria população de Cuba passou a desconfiar."

Durante o período da Guerra Fria, os Estados Unidos, temendo perder sua influência para os soviéticos, formaram diversas alianças com países latinos no intuito de evitar que os ideais comunistas se instalassem nesses países e prejudicassem a segurança americana. Com esse apoio americano, diversos países da América Latina adotaram regimes ditatoriais. Esses regimes foram sustentados por diversas instituições e estratégicas alianças internas e externas. No plano institucional, foi fundamental a criação de serviços secretos responsáveis pela proteção e manutenção do regime vigente, bem como pela viabilização de ações e práticas capazes de neutralizar a atuação dos movimentos de oposição e de infiltração comunista.

\section{Segurança e Inteligência na Concepção do Estado Brasileiro}

Mesmo estando o Brasil há mais de um século sem participar de conflitos externos, ainda se faz necessário manter uma política de segurança bem estruturada capaz de reagir de forma eficaz a uma possível agressão. Em reportagem de Bruno de Vizia, publicada em outubro de 2008 no jornal Gazeta Mercantil, o ministro de Assuntos Estratégicos da Presidência da República, Mangabeira Unger, ao falar sobre o Plano Nacional de Defesa, frisou "Queremos que a reorganização das Forças Armadas seja uma ocasião para nossa requalificação tecnológica duradoura" e completou, "De todos os grandes países da história moderna, o Brasil é o menos beligerante, mas o nosso pacifismo não nos exime da necessidade de nos defendermos adequadamente". 
Artigo original

Hegemonia - Revista Eletrônica de Relações Internacionais do Centro Universitário Unieuro ISSN: 1809-1261

UNIEURO, Brasília, número 5, 2010

Seguindo o mesmo pensamento, Guimarães enfatiza a necessidade de mantermos um potencial defensivo preparado, inclusive em períodos de paz, podendo-se obter por meio de políticas bem organizadas e com diferenciado conhecimento do potencial de seus vizinhos:

\footnotetext{
"... reconhecer que as despesas com segurança não têm, na maior parte dos países, nenhuma relação com inimigos ou ameaças próximas, mas sim com seus interesses de natureza política e econômica global. As despesas militares dos Estados Unidos nada têm a ver com ameaças mexicanas ou canadenses e as despesas da França nada têm a ver com a Espanha ou a Alemanha" (2004:47)
}

\section{Do SNI à ABIN: Uma Breve Retrospectiva}

Em 15 de abril de 1964 o general militar Humberto de Alencar Castelo Branco foi eleito Presidente da República pelo Congresso Nacional. Em sua posse declarou defender a democracia, mas quando iniciou o governo assumiu uma postura autoritária. Como ato inicial em seu mandato instituiu ainda, em seu governo, o bipartidarismo, que autorizava apenas o funcionamento de dois partidos: o Movimento Democrático Brasileiro (MDB) e a Aliança Renovadora Nacional (ARENA). O primeiro era de oposição, controlado pelo governo. O segundo representava os interesses dos aliados e defensores do regime militar. Em janeiro de 1967, o governo militar cria e impõe uma nova Constituição para o Brasil, aprovada no mesmo ano. A Constituição de 1967 legitima e institucionaliza o regime militar e suas formas de atuação.

Dentro deste cenário foi criado em 13 de junho de 1964 o Serviço Nacional de Informações (SNI), com a função de coordenar as atividades de informações e contra-informações, no Brasil e no exterior.

Mas origens da inteligência nacional vão muito além de 1964. Segundo Buzanelli (2004), os primeiros registros que se tem notícia são de 29 de novembro de 1927, quando o então Presidente da República, Washington Luiz criou o Conselho de Defesa Nacional (CDN) que, dentre outras, tinha a função de “coordenar a reunião de informações relativas à defesa da Pátria”.

O sistema de inteligência brasileiro obteve grande evolução com a criação do Serviço Federal de Informações e Contra-Informação (SFICI). Instituído através do decreto n. ${ }^{0}$ 9.775-A, de 
Artigo original

Hegemonia - Revista Eletrônica de Relações Internacionais do Centro Universitário Unieuro ISSN: 1809-1261

UNIEURO, Brasília, número 5, 2010

06 de setembro de 1946, pelo Presidente Eurico Gaspar Dutra, somente começou a funcionar cerca de dez anos depois, já no governo do Presidente Juscelino Kubitschek. Seu funcionamento ocorreu em um momento em que o Presidente JK estava bastante pressionado, tanto pelo governo norteamericano quanto pelos militares, já que uma possível popularização do comunismo no Brasil não os agradava.

O serviço foi criado com o objetivo de fornecer dados ao Conselho Nacional de Segurança sobre "ideologias extremistas", e, durante toda sua existência, foi visto como paranóico em relação à definição dos potenciais inimigos do "estado democrático de direito". Suas investigações passaram por grupos de esquerda, não importando se esses eram políticos ou não, e também foram investigados políticos da direita, rivais do presidente.

O governo norte-americano foi muito influente na criação do SFICI, Tosta Júnior (2009), apud Antunes (2001: 43-44), cita o fato de o governo brasileiro ter enviado aos EUA três militares e um delegado da Polícia Federal para receber informações e aprender técnicas para, em seu retorno, aplicar esses conhecimentos no Brasil.

\section{O Serviço Nacional de Informações (SNI)}

Criado com uma estrutura muito superior à de seu sucessor, SFICI, o SNI foi o principal órgão responsável pelas atividades de "informações" no Brasil, principalmente no período compreendido entre 1969 e 1984. Seguindo as coordenadas do governo americano, o SNI incorporou aos seus documentos fichas de todas as principais lideranças políticas, sindicais e empresariais do Brasil. O poder institucional do chefe do SNI, que tinha status de ministro, era imenso, sendo em algumas oportunidades comparado ao do Chefe de Estado, podendo inclusive expulsar um investigado do País. Dentro de sua estrutura organizacional, o SNI possuía uma agência central que controlava todas as informações que chegavam das agências regionais, catalogando, processando e após devolvendo para as agências de competência para então efetuar operações ou arquivá-las.

Importante ressaltar que, segundo Buzanelli (2004), a Escola Superior de Guerra (ESG) teve muita influência no processo de formação do pensamento estratégico nacional voltado à Inteligência, como também tiveram influência agências externas como a CIA, sendo que esta auxiliou na formulação da doutrina brasileira de Inteligência. Foi nesse período que, através do $1^{\circ}$ Plano Nacional de Informações (PNI) em 1970 foi instituído o Sistema Nacional de Informações 
Artigo original

Hegemonia - Revista Eletrônica de Relações Internacionais do Centro Universitário Unieuro ISSN: 1809-1261

UNIEURO, Brasília, número 5, 2010

(SisNI). Muito do que se sabe a respeito da Inteligência hoje é resultado de formulações práticas e estudos realizados no período do SNI, como o SisNI, que foi precursor do atual Sistema Brasileiro de Inteligência (Sisbin). Em 31 de março de 1971, foi criada a Escola Nacional de Informações (EsNI), precursora da atual Escola de Inteligência (EsInt). Com a criação da EsNI, todo o processo de formação e capacitação dos profissionais de Inteligência deixou de ser executado pela ESG, no Rio de Janeiro, e passou a ser responsabilidade da EsNI, com sede em Brasília.

\section{Agência Brasileira de Inteligência}

Ao iniciarmos o estudo sobre a Agência Brasileira de Inteligência, Antunes nos mostra como trabalhar com os temas Informação e Inteligência:

"De forma a dinamizar a leitura e compreensão do texto, optamos por utilizar os termos inteligência e informação da forma como eles surgem no debate brasileiro. Foi em 1990 que o presidente Fernando Collor extinguiu o Serviço Nacional de Informações e criou, dentro da estrutura da nova Secretaria de Assuntos Estratégicos, a Subsecretaria de Inteligência. É certo que, nos serviços de informações das Forças Armadas, já havia, desde o começo da década de 1980, discussões a respeito da renomeação da atividade. (...)" (2002:12)

A partir de então, o termo informações, muito utilizado com o SFICI, SNI e outras agências, passa a ser apresentado como inteligência. Com esta modificação, tenta-se retirar um pouco da imagem negativa que o termo "informações" traz consigo como herança do próprio regime militar. Este trabalho não tem por objetivo analisar as negociações que deram origem à lei, para tal recomenda-se a obra de Priscila Antunes.

\section{A Lei n. ${ }^{\circ} 9.883$}

A Agência Brasileira de Inteligência foi instituída por meio da Lei n. ${ }^{\circ}$ 9.883, de 07 de dezembro de 1999, sancionada pelo então presidente Fernando Henrique Cardoso. Segundo 
Artigo original

Hegemonia - Revista Eletrônica de Relações Internacionais do Centro Universitário Unieuro ISSN: 1809-1261

UNIEURO, Brasília, número 5, 2010

Gonçalves (2002), a referida Lei foi um marco para a atividade de Inteligência do Brasil, pois criava uma agência civil nova e voltada para a Inteligência estratégica.

A Lei, em seu artigo primeiro, institui o Sistema Brasileiro de Inteligência (Sisbin), integrante das ações de planejamento e execução das atividades de Inteligência do Brasil, com a finalidade de fornecer ao Presidente da República, subsídios relativos a assuntos de interesse nacional. Em seu §2, coloca que Inteligência é: “atividade que objetiva a obtenção, análise $e$ disseminação de conhecimentos dentro e fora do território nacional sobre fatos e situações de imediata ou potencial influência sobre o processo decisório e a ação governamental e sobre a salvaguarda e a segurança da sociedade e do Estado." Se a inteligência objetiva a obtenção do Conhecimento, sendo ele no País ou fora, o $\$ 3$ trata da proteção deste contra serviços de inteligência externos, a contra-inteligência. "Entende-se como contra-inteligência a atividade que objetiva neutralizar a inteligência adversa".

A Lei estabelece também que o Sistema Brasileiro de Inteligência, através de ato do Presidente da República, será composto pelos órgãos e entidades da Administração Pública Federal, que direta ou indiretamente possam produzir conhecimentos de interesse da atividade de inteligência, principalmente os responsáveis pelas seguintes áreas: defesa externa, segurança interna e relações exteriores. Além desses, pode-se criar convênios com as Unidades da Federação para a composição do Sisbin, depois de ouvido o órgão de controle externo da atividade de inteligência. Amaral faz referência a este órgão. "No caso do controle externo, trata-se da Comissão Mista (CCAI), composta pelos líderes da maioria e da minoria na Câmara dos Deputados e no Senado Federal, pelos presidentes das Comissões de Relações Exteriores e Defesa Nacional (Credens) das duas Casas; e do Tribunal de Contas da União" (2009).

Com a finalidade de planejar, executar, coordenar, supervisionar e controlar as atividades de Inteligência do País, com a Lei foi também criada a Agência Brasileira de Inteligência (ABIN), órgão central do Sisbin. O artigo terceiro especifica que a ABIN deve obedecer às políticas e às diretrizes superiormente traçadas nos termos da Lei. A respeito de políticas, Amaral faz questão de ressaltar que "a ABIN não define políticas, mais sim trabalha em função da política estabelecida por outras instâncias. Essa definição é feita por instâncias superiores, como o Gabinete de Segurança Institucional da Presidência da República (GSI/PR), na qual a Agência está subordinada. À ABIN corresponde uma Política Nacional de Inteligência" que, por ser uma "política", não é ela que define. A própria Lei em seu art. $5^{\circ}$ deixa claro que a competência de fixação da Política Nacional de Inteligência é do Presidente da República. 
Artigo original

Hegemonia - Revista Eletrônica de Relações Internacionais do Centro Universitário Unieuro ISSN: $1809-1261$

UNIEURO, Brasília, número 5, 2010

Por tratar de assuntos e conteúdos sensíveis, e para não ferir o que consta no art. 37 da Constituição Federal do Brasil, que diz que a administração pública direta e indireta de qualquer dos Poderes da União, dos Estados, do Distrito Federal e dos Municípios devem obedecer entre outros ao princípio da publicidade, é que o art. $9^{\circ}$ informa que os atos da ABIN, cuja publicidade possa comprometer o êxito de suas atividades sigilosas, deverão ser publicados em extrato. Importante ressaltar que foi incluído no corpo da legislação que todos os atos referentes ao funcionamento da Agência e a seus funcionários deverão obrigatoriamente constar em extrato.

Nem todos os pontos relativos ao sigilo do conhecimento vieram com a Lei n. ${ }^{\circ}$ 9.883, por esse motivo que, em 31 de agosto de 2001, a Presidência da República editou a Medida Provisória n. ${ }^{\circ}$ 2.216-37, e inseriu na Lei n. ${ }^{\circ} 9.883$ o art. $9^{\circ}$-A com a seguinte redação:

"Art. 9-A. Quaisquer informações ou documentos sobre as atividades e assuntos de inteligência produzidos, em curso ou sob a custódia da ABIN somente poderão ser fornecidos, às autoridades que tenham competência legal para solicitá-los, pelo Chefe do Gabinete de Segurança Institucional da Presidência da República, observado o respectivo grau de sigilo conferido com base na legislação em vigor, excluído aqueles cujo sigilo seja imprescindível à segurança da sociedade e do Estado.

$\S 1^{\circ} \mathrm{O}$ fornecimento de documentos ou informações, não abrangidos pelas hipóteses previstas no caput deste artigo, será regulado em ato próprio do Chefe do Gabinete de Segurança Institucional da Presidência da República.

$\S 2^{\circ}$ A autoridade ou qualquer outra pessoa que tiver conhecimento ou acesso aos documentos ou informações referidos no caput deste artigo obriga-se a manter o respectivo sigilo, sob pena de responsabilidade administrativa, civil e penal, e, em se tratando de procedimento judicial, fica configurado o interesse público de que trata o art. 155, inciso I, do Código de Processo Civil, devendo qualquer investigação correr, igualmente, sob sigilo."

No caput do artigo, o legislador informa que os documentos sob custódia da ABIN poderão, 
Artigo original

Hegemonia - Revista Eletrônica de Relações Internacionais do Centro Universitário Unieuro ISSN: 1809-1261

UNIEURO, Brasília, número 5, 2010

caso necessário, ser solicitados por outro órgão, mas nesse caso, o órgão que o solicite deve ter competência legal para tal ato e deve fazê-lo por meio do GSI. Este artigo é importante e determina as condições necessárias para a comunicação da Agência com os demais órgãos externos.

Sendo mais abrangente, o $\S 2^{\circ}$ envolve e descreve responsabilidades para todas as pessoas que por qualquer razão tenham posse de documentação ou informações, que por seu conteúdo necessitem de sigilo.

Com a criação do Sisbin e da ABIN, a Lei n. ${ }^{\circ} 9.883$ também cria a estrutura organizacional da Agência, informando que a mesma possuirá o cargo de Diretor-Geral e Diretor-Adjunto, onde a escolha do primeiro cargo é privativa do Presidente da República, necessitando da aprovação de seu nome pelo Senado Federal.

\section{A ABIN na Prática}

Como já foi citado anteriormente, a ABIN é subordinada diretamente à Presidência da República, através do GSI, hoje comandada pelo General-de-Exército Jorge Armando Felix. A Agência é dirigida pelo Diretor Geral Substituto, Sr. Wilson Roberto Trezza. Por essa razão em alguns casos, percebe-se o Gen. Jorge Felix falando em nome da ABIN, o que não ocorria quando a Agência foi criada. Antunes cita a relação que existia entre o GSI e a ABIN, que deixava a Agência cada vez mais subordinada ao GSI e não à Presidência.

"... é estranho que em praticamente todas as ocasiões em que há declarações do Executivo sobre alguma coisa relacionada à agência elas sempre envolveram o General Alberto Cardoso. É ele quem ordena levantamentos, que fala para a imprensa sobre a ABIN, quem dirige suas atividades. No entanto, seria interessante lembrar que uma das formas de controle externo do Legislativo sobre o sistema de inteligência seria a aprovação pelo Senado do nome indicado para diretor-geral da ABIN, portanto a pessoa indicada para realizar sua administração. O General Alberto Cardoso nunca teve seu nome submetido à aprovação do Senado. Quem teve seu nome aprovado em 15 de março de 2000, após votação secreta que obteve 60 votos a 
Artigo original

Hegemonia - Revista Eletrônica de Relações Internacionais do Centro Universitário Unieuro

ISSN: 1809-1261

UNIEURO, Brasília, número 5, 2010

favor e sete contra, foi o coronel Ariel de Cunto. O coronel De Cunto está aparecendo como figurante dessa história" $(2002: 192)$

Oficialmente, a ABIN deixou de ser subordinada diretamente à Presidência da República em janeiro de 2000, quando o então Presidente Fernando Henrique Cardoso sancionou a Medida Provisória n. ${ }^{\circ}$ 1999-4, subordinando-a ao GSI. O povo brasileiro ainda guarda lembranças não muito agradáveis dos períodos em que os militares estiveram no comando do País, e, em conseqüência disso, não recebem de maneira agradável nada que esteja ligado a esse período, se enquadrando aí principalmente as atividades de Inteligência, o que remete a "Informações" e ao SNI. Mas a atividade de Inteligência brasileira ao longo dos anos deixou de ser militar e se tornou civil, tendo como órgão central uma agência civil, que, a partir da criação da Escola de Inteligência, transferiu da ESG a instrução dos profissionais da Inteligência.

Antunes (2002) faz importante comentário a respeito da seleção dos servidores da ABIN, informando que a agência é a única no mundo que seleciona seus servidores através de concurso público. Democraticamente, o mais correto, mas abre brechas para a entrada de pessoas não tão preparadas e comprometidas com a Inteligência.

Esses fatores tentam colocar a Agência mais próxima da sociedade, desvencilhando-a do "passado sombrio" do período militar. Hoje a ABIN possui um programa que leva os jovens para dentro da Agência para conhecerem as atividades desenvolvidas, objetivando mostrar uma boa imagem da Inteligência.

\section{Considerações Finais}

O Estado Brasileiro tem passado por inúmeras transformações no decorrer das últimas décadas, tanto nas áreas econômica e financeira como nas áreas políticas e sociais. Saímos de um regime ditatorial e chegamos a uma democracia, que, cada vez mais, se consolida e beneficia todos com suas garantias e direitos constitucionais. Paralelamente, esses fatores de transformação também influenciaram diversos países pelo mundo, em especial na América Latina.

Observamos a bipolarização mundial. Ficamos no meio de uma guerra ideológica em que os dois principais atores não se enfrentaram diretamente e formalmente, mas produziram tensões e alinhamentos políticos diversos. 
Artigo original

Hegemonia - Revista Eletrônica de Relações Internacionais do Centro Universitário Unieuro ISSN: 1809-1261

UNIEURO, Brasília, número 5, 2010

Passamos do risco da guerra nuclear à quebra de um dos lados da balança, e com isso o mundo parou para pensar. Cogitaram que a história tinha chegado ao fim, mas, o que ocorre após o fim da história?

A Inteligência foi criada, aperfeiçoada, criticada e, por fim, rejeitada. O trauma que ficou como resquício dos períodos violentos impostos pelas ditaduras permaneceu com a chegada da democracia. Mas, devido ao reconhecimento de sua importância, surgiu a necessidade de criação de uma agência estatal nacional, cuja função é superintender e coordenar as atividades de Informações e contra-informações do Brasil.

Nesse contexto, a Agência Brasileira de Inteligência exerce, desde 07 de dezembro de 1999, embasado em seu lema "A Inteligência em defesa da sociedade, do estado democrático de direito e dos interesses nacionais", importante e discreta tarefa para a segurança do País.

\section{Referências Bibliográficas.}

\section{Entrevistas:}

Roniere Ribeiro do Amaral. Brasília: 07 mai. 2009. Professor da Escola de Inteligência.

Tese:

GONÇALVES, Joanisval Brito. Sed quis custodiet ipso custodes? O controle da atividade de inteligência em regimes democráticos: os casos de Brasil e Canadá. Brasília: UnB, 2008. 797p. Tese (Doutorado) - Programa de Pós-Graduação em Relações Internacionais, Instituto de Relações Internacionais, Universidade de Brasília, Brasília, 2008.

\section{Legislação:}

Lei n. ${ }^{\circ} 4.341$, de 13 de junho de 1064.

Ato Institucional n. ${ }^{\circ}$ 5, de 11 de dezembro de 1968.

Lei n. ${ }^{\circ} 8.159$, de 08 de janeiro de 1991.

Lei n. ${ }^{\circ}$ 9.883, de 07 de dezembro de 1999.

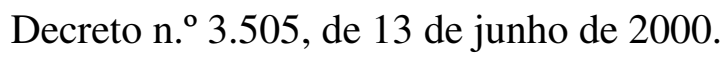


Artigo original

Hegemonia - Revista Eletrônica de Relações Internacionais do Centro Universitário Unieuro

ISSN: 1809-1261

UNIEURO, Brasília, número 5, 2010

Medida Provisória n. ${ }^{\circ}$ 2.216-37, de 31 de agosto de 2001.

Decreto n. ${ }^{\circ}$ 4.376, de 13 de setembro de 2002.

Decreto n. $^{\circ} 4.553$, de 27 de dezembro de 2002.

Decreto n. ${ }^{\circ} 5.301$, de 09 de dezembro de 2004.

Lei n. ${ }^{\circ} 11.111$, de 05 de maio de 2005.

\section{Livros e artigos:}

ANTUNES, Priscila Carlos Brandão. SNI \& ABIN: uma leitura da atuação dos serviços secretos brasileiros ao longo do século XX. Rio de Janeiro: Editora FGV, 2002.

BUZANELLI, Márcio Paulo. Evolução histórica da atividade de inteligência no Brasil. IX Congresso Internacional del CLAD sobre la reforma del Estado y de la Administración Pública, Madrid - Espanha, 2-5 nov. 2004.

CLAUSEWITZ, Carl Von. Da Guerra. São Paulo: Martins Fontes, 1996.

GUIMARÃES, Samuel Pinheiro. Uma estratégia militar para o Brasil. In: J.R. de Almeida Pinto, A. J. Ramalho da Rocha, R. Doring Pinho da Silva. (Org.) Reflexões sobre defesa e segurança: uma estratégia para o Brasil. Brasília: Ministério da Defesa, Secretaria de Estudos e de Cooperação, 2004. vol. 1.

HOBBES, Tomas. O Leviatã. São Paulo: Martins Fontes, 2003.

MAQUIAVEL, Nicolau. O Príncipe. São Paulo: Martins Fontes, 1998.

MORGENTHAU, Hans J. A política entre as nações: a luta pelo poder e pela paz. Brasília: UnB, 2003.

PECEQUILO, Cristina Soreanu. Introdução às relações internacionais: temas, atores e visões. Petrópolis, RJ: Vozes, 2004.

SARFATI, Gilberto. Teoria das Relações Internacionais. São Paulo: Saraiva, 2005.

TOSTA JUNIOR, Wilson Machado. O Serviço Federal de Informações e Contra-Informação: depoimentos e controvérsia em fragmentos da história. Pró-Defesa.

\section{Dicionário:}

HOUAISS, Antônio; VILLAR, Mauro de Salles. Minidicionário Houaiss da língua portuguesa. 2. ed. Rio de Janeiro: Objetiva, 2004. 907p. 
Artigo original

Hegemonia - Revista Eletrônica de Relações Internacionais do Centro Universitário Unieuro ISSN: 1809-1261

UNIEURO, Brasília, número 5, 2010

\section{Jornal:}

VIZIA, Bruno. Plano de defesa prevê proteção dos recursos energéticos. Gazeta Mercantil, São Paulo, 14 out. 2008. Caderno A, página 4.

\section{Internet:}

http://pt.wikipedia.org/wiki/NKVD, acessado em 10 de abril de 2009.

http://pt.wikipedia.org/wiki/KGB, acessado em 10 de abril de 2009.

http://pt.wikipedia.org/wiki/Gestapo, acessado em 10 de abril de 2009.

http://pt.wikipedia.org/wiki/MI5, acessado em 10 de abril de 2009.

http://pt.wikipedia.org/wiki/Central_Intelligence_Agency, acessado em 10 de abril de 2009.

http://veja.abril.com.br/historia/crise-dos-misseis/especial-capa-eua-urss.shtml, acessado em 10 de abril de 2009. 